DOI: $10.25100 /$ pfilosofica.v0i50.8902

\title{
DEMOCRACIA Y LIBERTAD EN B. SPINOZA
}

\section{Jorge-Aurelio Díaz Mario-David Fernández-Mora}

Universidad Católica de Colombia, Bogotá, Colombia. Universidad Nacional de Colombia, Bogotá, Colombia.

\section{Resumen}

Negar el libre albedrío implica que el ser humano no es libre por naturaleza, sino que puede llegar a serlo mediante un uso adecuado de su inteligencia; libertad que solo la consiguen los "sabios". Por eso, cuando Spinoza entiende la democracia como la forma de gobierno que mejor defiende la libertad, esto vale para los "sabios", pero no para el vulgo, que solo mediante el miedo y la esperanza es conducido a obrar según los dictados de la razón. ¿No será esta indeseable consecuencia la que le impidió terminar su Tratado Político, precisamente cuando se aprestaba a estudiar la democracia?

Palabras clave: Política; democracia; libertad; libre albedrío, naturaleza humana.

Cómo citar este artículo: Díaz, J.A. (2020). Democracia y libertad en B. Spinoza. Praxis Filosófica, (50S), 11-24. doi: 10.25100/pfilosofica.v0i50.8902.

Recibido: 8 de octubre de 2019. Aprobado: noviembre 10 de 2019. 


\title{
Democracy and Freedom According to B. Spinoza
}

\author{
Jorge-Aurelio Díaz ${ }^{1}$ \\ Mario-David Fernández-Mora ${ }^{2}$
}

\begin{abstract}
The negation of free will implies that a human being is by nature not free, unless he or she can become so by rightly using his or her intellect. If so, freedom would be a privilege reserved only for the "wise men". Consequently, when Spinoza identifies democracy as the form of government that best defends human freedom, learned men become its sole beneficiaries. Therefore, the "common herd" is not protected because only fear or hope nudges the ordinary populace to follow the commands of reason, rather than rational thought. Could this undesirable consequence be what hindered Spinoza in the completion of his Political Treatise, just as he was prepared to study the nature of democracy?
\end{abstract}

Keywords: Politic; Democracy; Freedom; Free Will, Human nature.

${ }^{1}$ Doctor en filosofía por la Université Catholique de Louvain (Bélgica); Profesor emérito de la Universidad Nacional de Colombia; Profesor del Departamento de Humanidades de la Universidad Católica de Colombia; Director del Grupo de investigación Philosophia Personae (COL0091564). Sus últimas publicaciones son las siguientes: (2019). Educación, política y universidad. Analecta Política, IX(16), 37-54; (2018). Fe bíblica y filosofía. Franciscanum, LX, 143-168. ORCID: 0000-0001-8576-0815 E-mail: jadiaza@ucatolica.edu.co

${ }^{2}$ Politólogo, candidato a Magister en Filosofía por la Universidad Nacional de Colombia, Máster 1 en Ciencias Políticas por la Universidad Paris 8. E-mail: mariofernandezmora@ gmail.com 
DEMOCRACIA Y LIBERTAD EN B. SPINOZA

\author{
Jorge-Aurelio Díaz \\ Mario-David Fernández-Mora \\ Universidad Católica de Colombia, Bogotá, Colombia. \\ Universidad Nacional de Colombia, Bogotá, Colombia.
}

\title{
I. La política en la filosofía de Spinoza
}

No cabe duda de que la filosofía de Baruj Spinoza, como lo indica expresamente el inicio de su Tratado de la reforma del entendimiento (TIE), es ante todo una reflexión personal en búsqueda "de algo que fuera un bien verdadero y capaz de comunicarse, y de tal naturaleza que por sí solo, rechazados todos los demás, afectara el ánimo" (TIE, 1). Sin embargo, su preocupación por la forma de organizarse la sociedad en cuyo seno debe llevarse a cabo dicha reflexión, en otras palabras, por la política, se hace presente a todo lo largo de su obra, porque él sabe muy bien que "el hombre que se guía por la razón es más libre en el Estado donde vive según leyes que obligan a todos, que en la soledad donde sólo se obedece a sí mismo" (E4P73).

En efecto, en esa tarea de reformar el entendimiento y determinar en qué consiste el bien supremo, es claro que podemos concebir una naturaleza humana mucho más firme que la que tenemos, y que, además, estamos en condiciones de conseguirla; y es precisamente este ideal de perfeccionamiento personal el que viene a constituir nuestro bien supremo, de modo que los medios de que dispongamos para alcanzarlo pueden considerarse ellos mismos como bienes (cf. TIE, 13): 
Ese es entonces el fin al que tiendo: adquirir tal naturaleza y procurar que muchos la adquieran conmigo; es decir, que a mi felicidad pertenece contribuir a que otros muchos entiendan lo mismo que yo, a fin de que su entendimiento y su deseo concuerden totalmente con mi entendimiento y con mi deseo. Para que eso sea efectivamente así es necesario entender la Naturaleza, en tanto en cuanto sea suficiente para conseguir aquella naturaleza (humana). Es necesario, además, formar una sociedad tal como cabría desear a fin de que el mayor número posible de individuos alcance dicha naturaleza con la máxima facilidad y seguridad. (TIE, 14; resaltado agregado)

Spinoza ofrece aquí una visión de la política claramente más optimista que aquella que podemos encontrar en los textos posteriores, porque expresa su esperanza en la posibilidad de "formar una sociedad tal como cabría desear a fin de que el mayor número posible de individuos alcance dicha naturaleza con la máxima facilidad y seguridad". Más tarde esta esperanza parece haber desaparecido, o haberse al menos ensombrecido, ante la dura realidad que nos muestra cómo la mayoría de las personas no aspiran o no pueden aspirar a regir su vida a la luz de la razón. Ahora bien, ya en el mismo TIE, Spinoza tuvo clara consciencia de que optar por la filosofía como forma de organizar su propia vida implicaba tomar distancia del vulgo, con el que, sin embargo, tenía que seguir conviviendo. De ahí las conocidas tres normas de vida que establece para ello:

\begin{abstract}
$1^{\text {a }}$ Hablar según la capacidad del vulgo y hacer todo aquello que no constituya impedimento alguno para alcanzar nuestra meta. [...] $2^{\mathrm{a}}$ Disfrutar de los placeres en la justa medida en que sea suficiente para proteger la salud. $3^{\text {a }}$ Finalmente, buscar el dinero o cualquier otra cosa tan solo en cuanto es suficiente para conservar la vidia y la salud, y para imitar las costumbres ciudadanas que no se oponen a nuestro objetivo. (TIE, 16)
\end{abstract}

Ahora bien, será en el Tratado Teológico-Político (TTP) donde inaugure su reflexión específicamente política, en cuyo prefacio encontramos ya una dura crítica a las monarquías que suelen estar apoyadas por la religión en el uso de la superstición como medio de dominar "la masa":

Nada extraño, pues, que, bajo el pretexto de religión, la masa sea fácilmente inducida, ora a adorar a sus reyes como dioses, ora a execrarlos y a detestarlos como peste universal del género humano [...]. Ahora bien, el gran secreto del régimen monárquico y su máximo interés consisten en mantener engañados a los hombres y en disfrazar, bajo el especioso nombre 
de religión, el miedo con el que se los quiere controlar, a fin de que luchen por su esclavitud como si se tratara de su salvación, y no consideren una ignominia, sino el máximo honor, dar su sangre y su alma para orgullo de un sólo hombre. Por el contrario, en un estado libre no cabría imaginar ni emprender nada más desdichado, ya que es totalmente contrario a la libertad de todos adueñarse del libre juicio de cada cual mediante prejuicios o coaccionarlo de cualquier forma (TTP Praef, 6-7).

El texto del TTP lleva a cabo una extensa e interesante interpretación de la Biblia, con el propósito, en primer lugar, de establecer una clara diferenciación entre la filosofía y la teología; labor cuyo resultado lo resume muy bien el título del capítulo XIII, donde "se demuestra que la Escritura no enseña sino cosas muy sencillas, ni busca otra cosa que la obediencia". A partir de tal diferenciación, Spinoza pasa a estudiar, en el capítulo XVI, "los fundamentos del Estado; del derecho natural y civil del individuo, y del derecho de las supremas potestades"; y es ahí donde su preferencia por la democracia es expresada de manera contundente.

Comienza entonces por exponer la situación de los seres humanos en el estado natural, donde el único límite al derecho es el poder que tiene cada uno para autoafirmarse, sin importar los medios que utilice para ello; situación en extremo peligrosa que los obliga a salir de dicho estado por los innegables daños que conlleva:

Por eso debieron establecer, con la máxima firmeza y mediante un pacto, dirigirlo todo por el solo dictamen de la razón (al que nadie se atreve a oponerse abiertamente por no ser tenido por loco), y frenar el apetito en cuanto aconseje algo en perjuicio de otro, no hacer a nadie lo que no se quiere que le hagan a uno, y defender finalmente el derecho ajeno como el suyo propio (TTP, 191).

En pocas palabras, la necesidad de salir del estado natural lleva a los seres humanos a establecer como norma común de conducta la llamada regla de oro: "No hagas a los demás lo que no quieras que te hagan a ti". Pero dicha salida del estado natural conlleva asimismo la obligación de "cumplir absolutamente todas las órdenes de la potestad suprema, por más absurdas que sean, a menos que queramos ser enemigos del Estado y obrar contra la razón que nos aconseja defenderlo con todas las fuerzas" (TTP, 195, resaltado agregado). Y como esta conclusión ha sido el resultado de una clara argumentación, Spinoza considera "haber mostrado con suficiente claridad los fundamentos del Estado democrático". A lo que añade a continuación: "He tratado de él con preferencia a todos los demás, porque me parecía el 
más natural y el que más se aproxima a la libertad que la Naturaleza concede a cada individuo" (TTP, 195).

En cuanto al Tratado Político (TP), que desafortunadamente no fue concluido, cabía esperar que en él se habría de hallar la caracterización más detallada del sistema democrático, en contraste con el monárquico y el aristocrático, así como una clara justificación de su preferencia por él. Sin embargo, los cuatro parágrafos que alcanzó a redactar en el capítulo XI han suscitado, entre comentarista y traductores, no pocas discusiones en torno al alcance que se le da al término 'democracia'. Nos proponemos, entonces, ofrecer nuestra opinión al respecto.

\title{
II. EI concepto spinocista de democracia
}

Una de las cuestiones disputadas en torno a la forma como Spinoza comprende la democracia es si la misma debe entenderse como un fin o como un medio. Conocidos comentaristas, como Eugenio Fernández y Atilano Domínguez, la conciben como un fin en sí mismo, mientras que Alexandre Matheron considera que la democracia para Spinoza es solo un medio transitorio en el camino hacia la sociedad ideal.

Domínguez, además de ver en Spinoza uno de los mayores aportantes a la consolidación de la democracia liberal, defiende la tesis según la cual la democracia viene a ser el modelo de organización política más complejo, poderoso y libre. En su análisis del TP establece los criterios generales que utiliza Spinoza para examinar una forma de gobierno, y señala que:

\begin{abstract}
Spinoza aplica, pues, estos criterios a las distintas formas de gobierno. Aunque, en principio, sólo menciona las tres clásicas [monarquía, aristocracia y democracia], en su análisis y organización práctica distingue dos modalidades en las dos primeras. De ahí que trate sucesivamente de la monarquía absoluta y la constitucional, de la aristocracia centralizada y la descentralizada y, por fin, de la democracia. El resultado será que la monarquía es el régimen menos complejo y, al mismo tiempo, el menos fuerte y libre, mientras que la democracia será el más complejo, el más poderoso y el más libre. (Domínguez, 1992, p. 95).
\end{abstract}

Esta última aseveración acerca de la democracia es solo una conclusión que deriva Domínguez de su lectura del texto de Spinoza, porque, como se indicó, el TP nunca fue terminado, y se interrumpió precisamente cuando comenzaba a desarrollar el examen del régimen democrático. Veremos que esta conclusión puede ser discutida; pero, por el momento, digamos que, siguiendo una interpretación similar, aunque desde una orilla de pensamiento 
diferente, Eugenio Fernández lee también la democracia spinocista como el modelo en el que se realiza la potencia colectiva de la multitud, sin necesidad de que alguien aliene o enajene su potencia, y con la posibilidad de disfrutar de un máximo de libertad e igualdad. La democracia sería así el fin último y la mejor forma de organización social, en la que se realiza el individuo como agente libre:

La potencia de la multitud, principio constituyente de toda institución política, requiere como organización más adecuada la democracia. Sólo en ella la multitud íntegra, entera e integrada, tiene y ejerce todo el poder y el derecho, sin enajenación, ni acumulación, ni sometimiento (TTP 16/193, TP 8/3,11/1). La democracia real es la organización política más natural y más libre, porque en ella la transferencia es sólo composición, y porque su funcionamiento es adecuado a su constitución (TTP 16, 195). La transferencia es aquí comunicación sin pérdida, no abandono o alienación, y «autorización», génesis y construcción adecuada de la soberanía. La constitución que TP explica no ya como una secuencia fines a medios, sino como verdadera secuencia genética causa a efectos, se realiza adecuadamente en la democracia. El poder, y no sólo la potencia, está en manos de la multitud. En ella no hay lugar para reyes o señores que se creen dioses y engañen con cantos de sirena (TP 7/1). En la medida en que es real, no hace a nadie siervo de otro, sino a todos ciudadanos iguales y libres que obedecen no por miedo sino por interés y deseo propios (TTP 5, p 74 y 16, p 195; TP 5/6).Por su génesis y estructura intensifica las fuerzas activas y maximaliza los encuentros positivos. Su ley suprema es el interés y la felicidad de sus miembros (Fernández, 123-124).

El tono no poco encomiástico con el que Eugenio Fernández nos presenta la concepción spinocista de la democracia suscita sin embargo algunos interrogantes. No resulta tan claro que la entrega del poder individual al pueblo, o "a la mayor parte de toda la sociedad de la que él es una parte" (TTP,195), como dice el mismo Spinoza, sea en realidad una "comunicación sin pérdida, no abandono o alienación, y «autorización», génesis y construcción adecuada de la soberanía", como la entiende Fernández. Porque el mismo Spinoza, siguiendo estrictamente su discurso racional, nos dice, como hemos señalado antes, que quien lleva a cabo tal abandono debe obedecer las órdenes de la potestad suprema "por más absurdas que sean" ( $i b d$.). Y si bien es cierto que en el Estado democrático "no hay lugar para reyes o señores que se creen dioses y engañen con cantos de sirena", cabe preguntar si ese pueblo o esa mayoría, a la que se reviste con la potestad suprema, estará conformada por personas "que se guían por 
la razón", o si, de acuerdo con el mismo Spinoza, debemos pensar que "está muy lejos que todos puedan ser fácilmente conducidos por la sola guía de la razón, ya que cada uno es arrastrado por su placer, y la mente está casi siempre tan ocupada por la avaricia, la gloria, la envidia, la ira, etc., que no queda espacio alguno para la razón" (TTP, 192-193). Tal vez las debilidades crecientes que presentan los regímenes democráticos en nuestros días nos deberían llevar a moderar un tanto nuestro optimismo.

De modo que la posición que asume Alexandre Matheron el respecto tal vez pueda ofrecernos una consideración algo más sobria del concepto spinocista de democracia. El comentarista francés señala que no hay propiamente, en la obra de Spinoza, una defensa de la democracia como un fin, sino únicamente como un medio transitorio para la realización de una república de los sabios en la que no es necesaria ninguna forma de organización de gobierno. Matheron, además de criticar la noción de democracia en el TP porque excluye a los siervos y a las mujeres de la ciudadanía (sobre una justificación débil, a partir de su condición de alteris juris de los primeros y de inferioridad de las segundas), expresa que la política, y en este caso la democracia, es solo un medio para la culminación del proyecto filosófico de Spinoza:

Pero, en cuanto a la Política, ella nunca fue la última palabra de Spinoza: ella no es más que un momento de su proyecto filosófico. Más allá del Estado, incluso más allá del Estado más democrático posible, el modelo ideal que él se fija en materia de relaciones interhumanas es una comunidad de sabios liberados de todo constreñimiento, en la que cada uno, bajo la conducción de su sola razón, obraría de manera espontánea de acuerdo con todos, sin estar sometido a ninguna autoridad exterior (Matheron, 1977, p. 199).

Puede pensarse muy bien que, siguiendo la lógica del discurso spinocista, el ideal de sociedad vendría a ser aquella compuesta por sabios, es decir, por personas que "se guían por la razón"; sin embargo, la idea misma de una tal sociedad presenta al menos dos graves inconvenientes. El primero es que pensar en una sociedad de sabios no sería diferente a pensar como nos dice Spinoza que lo hacen los filósofos cuando pretenden elaborar una teoría política partiendo de los meros conceptos, ya que "conciben a los hombres, no como son, sino como ellos quisieran que fuesen", y elaboran así una política que, "o debería ser considerada como una quimera, o solo podría ser instaurada en el país de la Utopía, o en el siglo dorado de los poetas, allí donde no hacía falta alguna" (TP, 273). Y, segundo inconveniente, no resulta 
plausible considerar, como parece indicarlo Matheron, que Spinoza haya pensado alguna vez en la posibilidad de una tal sociedad de sabios. Si en el TIE, como pudimos verlo, habla de la necesidad de "formar una sociedad tal como cabría desear a fin de que el mayor número posible de individuos alcance dicha naturaleza con la máxima facilidad y seguridad" (TIE, 14), en el resto de sus escritos da muestras de un realismo acerca del vulgo que lo hace inmune a todo pensamiento utópico. ¿Qué pensar entonces de la concepción spinocista de la democracia?

\section{Problemas de la democracia spinocista}

Hemos podido ver cómo el concepto spinocista de democracia presenta algunos problemas; tratemos entonces de precisarlos, y de buscar el origen de los mismos. Para ello conviene realizar dos pequeños rodeos con el propósito de diferenciar con claridad dos maneras de comprender la libertad individual, y dos maneras de comprender la libertad colectiva.

En cuanto al primer rodeo, es importante tener en cuenta que la libertad individual puede considerarse simplemente como la capacidad que tienen los seres humanos de obrar siguiendo los dictados de su razón. Vista así, es algo que puede fácilmente constatarse, ya que desde el estudiante que decide realizar sus tareas en lugar de mirar la televisión, hasta el héroe o la heroína que sacrifican su vida en beneficio de sus semejantes, son claros ejemplos de dicha libertad. Además, esta manera de entender la libertad individual explica muy bien la articulación de los actos propiamente humanos, porque, si entendemos, como lo hace Tomás de Aquino siguiendo a Aristóteles ( $c f$. S. Th. I $^{\mathrm{a}}-\mathrm{II}^{\text {ae }}$, q. 83, a. 3), que la voluntad humana es un apetito racional, se entiende muy bien que ella decida, es decir, que pase de la potencia al acto movida por el bien apetecible que le presenta el intelecto. A su vez, esta forma de entender la libertad individual implica una comprensión restrictiva de lo que cabe llamar un acto humano, porque este solo tiene lugar cuando el individuo obra siguiendo la guía de su razón. En caso contrario no cabría hablar con propiedad de un acto humano, ya que obrar en contra de los dictados de la razón solo podría explicarse de dos maneras: o bien que el intelecto se ha equivocado el confundir un bien aparente con uno verdadero, y se trata entonces de un error, es decir, que no se ha obrado en contra de lo que dicta la razón, sino esta se ha cometido un error; o bien, que la voluntad no ha tenido la fuerza suficiente para vencer el impulso de las pasiones, caso en el cual no habría propiamente una acción, sino una pasión. Además, y esto es muy importante, la libertad comprendida así no es propiamente un atributo de la naturaleza humana, es decir, los seres humanos no son libres por naturaleza, sino que pueden llegar a serlo en la medida en que logren 
pensar de manera adecuada; es entonces y solo entonces cuando acceden al ejercicio de su libertad.

Esta es precisamente la manera como Spinoza entiende al ser humano cuando, en la segunda parte de su Ética, expone su visión antropológica. Recordemos que uno de los propósitos centrales de las dos primera partes de la Ética, las cuales configuran las bases de su sistema filosófico, es precisamente demostrar cómo ni en Dios (primera parte), ni en los seres humanos (segunda parte), se puede hablar de un libre albedrío; la única libertad de la que cabe hablar, tanto en Dios como en los seres humanos, es de la capacidad de seguir los dictados de la razón. Es cierto que en Dios (o la Naturaleza) ello se lleva a cabo sin ningún impedimento, mientras que en los seres humanos suelen intervenir las pasiones que impiden dicho ejercicio. ${ }^{3}$

Ahora bien, la libertad individual puede ser pensada también como un libre albedrío, caso en el cual la voluntad no es considerada como un apetito racional, sino como una facultad realmente autónoma, capaz de decidir por sí misma si obedece o no lo que le dicta la razón. Es claro que necesita del intelecto para obrar, ya que es este el que le ofrece las diversas posibilidades para ello; pero no se halla sometida al mismo, como es el caso en la manera anterior de comprender la libertad individual. El intelecto es entonces condición necesaria para el ejercicio de la voluntad, pero no es condición suficiente; hace falta que la voluntad decida si obedece o no a sus dictados. En este caso los seres humanos sí se consideran libres por naturaleza, porque disponen de una voluntad realmente autónoma que les permite decidir por sí mismo si obran o no según les dicta su razón. Cuando se obra desobedeciendo los dictados de la razón, no significa necesariamente que haya habido un error y que la voluntad haya sido débil, sino que bien puede haber abusado de su autonomía, como sucede en el caso del pecado.

Sin embargo, como bien sabemos, el grave inconveniente que tiene esta forma de entender la libertad individual, es decir, el libre albedrío, es que vuelve incomprensible para la razón el acto propiamente humano. ¿Cómo explicar que la voluntad pase por sí misma de la potencia al acto? Precisamente en esta imposibilidad de explicar racionalmente el acto libre se apoya la argumentación de Spinoza en contra del libre albedrío.

Como muy bien lo ha hecho notar I. Kant en la Fundamentación para una metafisica de las costumbres (2012), la única manera posible de justificar nuestra innegable consciencia de tener deberes es presuponer que podemos cumplirlos, es decir, que somos libres; pero, si bien es clara la necesidad

\footnotetext{
${ }^{3}$ En un interesante artículo titulado "Las conciencia errónea. De Sócrates a Tomás de Aquino" (2013), Alejandro Vigo presenta un excelente exposición de esta tesis, atribuida en sus orígenes a Sócrates.
} 
de dicho presupuesto, la idea misma de libertad "es algo que jamás se deja comprender por ninguna razón humana" (FMC A 124). Kant está pensando, por supuesto, en la libertad como libre albedrío. ${ }^{4}$

Una vez que hemos precisado la diferencia entre las dos maneras de entender la libertad individual, y haber señalado algunas de las consecuencias que conllevan, podemos iniciar el segundo rodeo, esta vez para examinar la doble manera de comprender la libertad en tanto que libertad colectiva. Para lo cual podemos recordar el Discurso sobre la libertad de los antiguos comparada con la de los modernos, pronunciado por Benjamin Constant en el Ateneo Real de París en el año 1819. Como bien lo recoge el título de su discurso, el orador se concentra en hacer una comparación entre la libertad moderna y la libertad antigua sobre la base de la distinción entre libertad positiva (la de los antiguos) y libertad negativa (la de los modernos). Se trata, claro está, de la libertad en sentido colectivo. Ahora bien, la primera, la de los antiguos, era de carácter político, y consistía en la posibilidad de un ejercicio activo sobre ciertos asuntos de la polis que, por sus efectos sobre lo colectivo, exigían la intervención constante de los ciudadanos. En palabras de Constant, se trataba de

[...] ejercer colectiva pero directamente varios aspectos incluidos en la soberanía: deliberar en la plaza pública sobre la guerra y la paz, celebrar alianzas con los extranjeros, votar las leyes, pronunciar sentencias, controlar la gestión de los magistrados, hacerles comparecer delante de todo el pueblo, acusarles, condenarles o absolverles (Constant, 1995, p. 53).

En esta versión de la libertad no había una noción de los derechos individuales, porque "el individuo, de algún modo, se había perdido en la nación, el ciudadano en la ciudad" (Constant, 1995, p. 54). En efecto, el ciudadano se hallaba sometido o sujeto a la autoridad colectiva, de modo que su libertad consistía en poder influir sobre los asuntos públicos, los cuales se presentaban en términos prácticos como un ejercicio de deliberación en la plaza pública para votar leyes, pronunciar sentencias, examinar gestiones de magistrados, juzgarlos, etc.

En contraste con esta libertad antigua, la libertad moderna no tiene un carácter directamente político, sino civil, ya que su objetivo se orienta a proteger la esfera individual ante posibles abusos o limitaciones externas. Consiste entonces, dice Constant, en "el derecho a no estar sometido sino a las leyes, de no poder ser detenido, ni condenado a muerte, ni maltratado

\footnotetext{
${ }^{4}$ Para un análisis más detallado sobre esta doble manera de comprender la libertad individual, puede verse el artículo de Jorge Aurelio Díaz (2017).
} 
de ningún modo por el efecto de la voluntad arbitraria de uno o varios individuos" (Constant, 1995, p. 52).

Esta libertad busca, entonces, la defensa de la voluntad individual contra toda injerencia de voluntades diferentes a la del individuo en su autonomía para dar opinión, escoger profesión, tener propiedad, desplazarse, reunirse con otros, etc. Es por ello por lo que también es denominada libertad negativa; porque no se refiere a un ejercicio activo del individuo, sino que busca impedir la intromisión de actores ajenos en la autonomía de sus decisiones para salvaguardar el goce de su independencia individual y privada, y hacer prevalecer la libertad individual o civil sobre la colectiva o política.

Si bien en su discurso Constant no entra a detallar el sentido de esa libertad individual que se propone salvaguardar la nueva concepción moderna de la libertad negativa, sí nos ofrece la oportunidad de conectar su propuesta con el concepto spinocista de democracia y descubrir en esta última la raíz de su problema más significativo. En efecto, tanto Constant como Spinoza concuerdan en que el propósito fundamental del Estado es la salvaguarda de la libertad personal. Sin embargo, el problema para Spinoza consiste en que su concepto de libertad individual, como hemos visto antes, implica que no se trata de un atributo que posean todos los seres humanos por naturaleza, ya que estos únicamente disponen de la posibilidad de lograrla mediante un adecuado ejercicio de su intelecto. Si Constant estima que la libertad negativa se propone salvaguardar una libertad individual propia de todos los ciudadanos, es porque está pensando realmente en una libertad como libre albedrío; ya que solo esta puede considerarse como un atributo de los seres humanos en virtud de su naturaleza.

En efecto, una vez que Spinoza ha descartado de raíz la posibilidad de que el ser humano disponga de un libre albedrío, la libertad individual que se propone salvaguardar la democracia viene a ser la de aquellos pocos que optan por orientar su vida a la luz de la razón. En otras palabras, la democracia que defiende Spinoza es el mejor sistema de gobierno, pero no lo es para todos los ciudadanos, sino únicamente para aquellos "sabios" que luchan por alcanzar la verdadera libertad racional, ya que son ellos los que disponen de una verdadera libertad individual. En cuanto al resto de los ciudadanos que, como hemos visto, están muy lejos de ser conducidos por la sola guía de la razón, "ya que cada uno es arrastrado por su placer, y la mente está casi siempre tan ocupada por la avaricia, la gloria, la envidia, la ira, etc., que no queda espacio alguno para la razón" (TTP, 193), ¿qué cabría hacer con ellos? 
Spinoza mismo nos ofrece en la Ética la solución al problema, solo que dicha solución presenta graves consecuencias para su defensa del sistema democrático. En efecto, cuando en la parte cuarta de la Ética procede a examinar "la esclavitud humana" y "la fuerza de los afectos", muestra muy bien cómo "los afectos de la esperanza y del miedo no pueden ser por sí mismos buenos" (E4P47), y cómo "la humildad no es virtud, es decir, no procede de la razón" (E4P53); y precisa luego, a continuación, en el escolio de la proposición 54:

Como los hombres rara vez viven según el dictamen de la razón, estos dos afectos, a saber, la humildad y el arrepentimiento, y, además de ellos, la esperanza y el miedo, traen más utilidad que daño. Y por eso, dado que hay que pecar, mejor es pecar por este lado. Pues si los hombres impotentes de ánimo fueran todos igualmente soberbios, no se avergonzaran de nada y nada temieran, ¿cómo podrían ser unidos y sujetos por algún vínculo? Causa terror el vulgo si no teme.

¿No sería entonces mejor, para estos ciudadanos que conforman la inmensa mayoría de la población, organizar la sociedad bajo un régimen autoritario como el que proponía Thomas Hobbes en su Leviathan? Porque, como lo señala Spinoza allí mismo, "quienes están sometidos a estos afectos pueden ser conducidos con mayor facilidad que los demás a que vivan finalmente bajo la guía de la razón, esto es, a que sean libres y gocen de la vida de los bienaventurados".

Podemos entonces preguntarnos si Spinoza llegó a entender el problema que implicaba su concepción de la libertad individual cuando se la confrontaba con su idea de democracia, y, al tomar conciencia de las consecuencias indeseables que de allíse derivaban, detuvo tal vez su escritura y no terminó de redactar ese capítulo XI con el que parecía completar el TP. Porque si se piensa la democracia desde la perspectiva del sabio, es decir, de quien se esfuerza por vivir a la luz de la razón, es cierto que se muestra como la mejor de las tres formas de gobierno, como aquella que salvaguarda mejor su búsqueda personal de libertad y felicidad; pero si se la piensa desde la perspectiva del vulgo, que es la propia y adecuada para la reflexión política, la democracia no solamente libera a los ciudadanos del miedo y la humildad, que sería el mejor modo de llevarlos a obrar según los dictados de la razón, sino que, además, y esto hace más grave la situación, somete al sabio mismo a las decisiones de una mayoría compuesta en su mayor parte de personas que no se rigen por la guía de la razón, y cuyas órdenes deberá obedecer, como nos indicó Spinoza, "por más absurdas que sean". 


\section{Referencias bibliográfícas}

Tomas de Aquino. (2001). Suma de Teología. Madrid, España: Biblioteca de Autores Cristianos. Recuperado de http://hjg.com.ar/sumat/

Constant, B. (1995). Discurso sobre la libertad de los antiguos comparada con la de los modernos (O. Godoy. Trad.). Estudios Públicos, (59), 51-68. Recuperado de https://www.cepchile.cl/cep/site/docs/20160303/20160303183535/rev59 godoy.pdf.

Díaz, J.-A. (2017). Pecado y autonomía. Praxis filosófica, (45), 259-283. doi:10.25100/filosófica.v0i45.6061.

Domínguez, A. (1992). Spinoza y el surgimiento de la democracia. Fragmentos de Filosofia, (12), 87-105.

Kant, I. (2012). Fundamentación para una metafisica de las costumbres (R. R. Aramayo. Trad.). Madrid, España: Alianza Editorial.

Matheron. A. (1977). Femmes et serviteurs dans la démocratie spinoziste. Revue Philosophique de la France et de l'Étranger, 167(2), 181-200.

Spinoza, B. (1925). Opera. Vol III. Heidelber, Alemania: Editorial Reviews.

Vigo, A. (2013). La conciencia errónea. De Sócrates a Tomás de Aquino. Signos Filosóficos, 15(29), 10-37. 